\title{
SOME SCALES OF EQUIVALENT WEIGHT CHARACTERIZATIONS OF HARDY'S INEQUALITY: THE CASE $q<p$
}

\author{
LaRs-ERiK Persson, Vladimir Stepanov and Peter Wall
}

Abstract. We consider the weighted Hardy inequality

$$
\left(\int_{0}^{\infty}\left(\int_{0}^{x} f(t) d t\right)^{q} u(x) d x\right)^{1 / q} \leqslant C\left(\int_{0}^{\infty} f^{p}(x) v(x) d x\right)^{1 / p}
$$

for the case $0<q<p<\infty, p>1$. The weights $u(x)$ and $v(x)$ for which this inequality holds for all $f(x) \geqslant 0$ may be characterized by the Mazya-Rosin or by the Persson-Stepanov conditions. In this paper, we show that these conditions are not unique and can be supplemented by some continuous scales of conditions and we prove their equivalence. The results for the dual operator which do not follow by duality when $0<q<1$ are also given.

Mathematics subject classification (2000): 26D10, 26D15.

Key words and phrases: integral inequalities, weighted Hardy's inequality.

\section{REFERENCES}

[1] A. Gogatishvili, A. Kufner, L. E. Persson And A. Wedestig, Real Anal. Exchange, 29, (2003/04), $867-880$.

[2] A. Kufner, L. E. Persson, Weighted Inequalities of Hardy Type, World Scientific, New Jersey/London/Singapore/Hong Kong, 2003.

[3] A. KufNer, L. MALigRANDA AND L. E. Persson, The Hardy inequality-about it's history and related results, accepted book manuscript, Department of Mathematics, Luleå University of Technology, 2006 (150 pages).

[4] V. MAZJA, Einbettungssätze für Sobolewsche Räume, Teil 1(Imbedding Theorems for Sobolev Spaces. Part 1), Teubner-Texte zur Mathematik, Leipzig, 1979.

[5] V. MAZJA, Sobolev Spaces, Russian Edition: Leningrad University, Leningrad 1985; English trans.: Springer Verlag, Berlin-Heidelberg, 1985.

[6] B. OPIC, A. KUfNER, Hardy-Type Inequalities, Longman, Harlow, 1990.

[7] L. E. Persson, V. D. StePANOV, Weighted integral inequalities with the geometric mean operator, J. Inequal. Appl., 7, (2002), 727-746 (an abbreviated version can be found in Dokl. Acad. Nauk., 377, (2001), 439-440).

[8] G. Sinnamon, V. D. Stepanov, The weighted Hardy inequality: new proofs and the case $p=1$, J. London Math. Soc., 54, (1996), 89-101. 